\title{
O SISTEMA FISCAL CHINÊS HOJE: TAX-SHARE SYSTEM
}

Jaderson Goulart Jr. ${ }^{1}$ Demian Castro ${ }^{2}$

Resumo: A segunda maior economia do mundo e uma das cinco experiências existentes do Socialismo Real, a China surpreende pela sua capacidade de crescimento, inovação e desenvolvimento. Embora seja definida como um Estado unitário, muitas de suas práticas são descentralizadas. Dessa maneira, esse trabalho traz um levantamento do sistema fiscal que há desde 1994 na China, o TaxShare System, detalhando seus impostos, os gastos orçamentários, e a questão regional. Além disso, foca também na divisão dessas variáveis entre os níveis de governo central e local.

Palavras-chave: China. Sistema Fiscal. Sistema Tributário. Finanças Públicas.

\section{CHINESE FISCAL SYSTEM TODAY: THE TAX-SHARE SYSTEM}

Abstract: The second largest economy in the world and one of the five existing experiences of Real Socialism, China surprises for its capacity for growth, innovation and development. Although it is defined as a unitary state, many of its practices are decentralized. In this way, this work brings a survey of the tax system that has existed since 1994 in China, the Tax-Share System, detailing its taxes, budget expenditures, and the regional issue. In addition, it also focuses on the division of these variables between the levels of central and local government.

Keywords: China. Fiscal System. Tax System. Public Finance.

\section{EL SISTEMA FISCAL CHINO HOY: TAX-SHARE SYSTEM}

Resumen: La segunda economía más grande del mundo y una de las cinco experiencias existentes del Real Socialismo, China sorprende por su capacidad de crecimiento, innovación y desarrollo. Aunque se define como un estado unitario, muchas de sus prácticas están descentralizadas. De esta manera, este trabajo trae un relevamiento del sistema tributario que existe desde 1994 en China, el Tax-Share System, detallando sus impuestos, gastos presupuestarios y el tema regional. Además, también se centra en la división de estas variables entre los niveles de gobierno central y local.

Palabras clave: China. Sistema Fiscal. Sistema de Impuestos. Finanza Pública.

\section{Introdução}

A organização do Estado chinês, segundo à sua Constituição de 1982 (REPÚBLICA POPULAR DA CHINA, 1982), é a seguinte: "A República Popular da

\footnotetext{
${ }^{1}$ Universidade Federal do Paraná, Programa de Pós-Graduação em Políticas Públicas, Curitiba, Brasil, Jaderson.junior@uol.com.br, https://orcid.org/0000-0001-7503-8343

${ }^{2}$ Universidade Federal do Paraná, Departamento de Ciências Econômicas e Programa de PósGraduação em Políticas Públicas, Curitiba, Brasil, demian@ufpr.br, https://orcid.org/0000-0001-55072050
} 
China é um Estado unitário multinacional, erguido conjuntamente pelos povos de todas as nacionalidades, entre os quais se estabeleceram e continuam a fortalecerem-se relações de igualdade, unidade e assistência mútua". Na teoria define-se como um Estado unitário, mas muitas das suas práticas de política econômica são, em certa medida, descentralizadas. Isto é, os governos locais têm responsabilidades quanto ao gasto e a arrecadação em certa medida.

A pedra fundamental da reforma é a divisão clara das competências tributárias: assim como no modelo da década de 1950, Divisão da Arrecadação, os níveis de governo têm uma determinação sobre qual base de arrecadação pertence a quem e qual é dividida entre os dois níveis. Uma mudança importante na forma de arrecadar, e baseada nesse mesmo princípio, foi a criação do National Tax Services e dos Local Tax Services, todos sob o controle do State Administration of Taxation. O primeiro é uma instituição que faz o recolhimento dos impostos que competem diretamente ao governo central e os que ele divide com as localidades; o segundo está a serviço das províncias e recolhe os tributos de sua competência; e o último é a entidade que regula e fiscaliza os dois primeiros, não permitindo mais a isenção ilegal por parte das províncias. ${ }^{3}$

Com a existência do State Administration of Taxation toda jurisprudência e legislação a respeito dos impostos cabe apenas ao governo central, incluindo o poder de definir a base de arrecadação e as alíquotas aplicadas - com uma exceção: as províncias podem definir a tarifa sobre o uso da terra urbana e dos vilarejos, mas mesmo assim dentro de uma variação máxima determinada. E quanto aos gastos não há regra definindo claramente a atribuição de cada nível de governo, nem mesmo quanto à empréstimos aos governos locais - em decorrência disso, a participação do governo central nos gastos continua caindo desde então. ${ }^{4}$

Este trabalho, então, está dividido em cinco seções, além desta introdução e das considerações finais: em primeiro lugar, uma breve evolução do Tax-Sharing System de 1994 até hoje, com as transformações nos impostos existentes e suas alíquotas; então, uma descrição detalhada dos impostos vigentes hoje, a base tributária e suas regras; em seguida, uma seção discorre sobre a divisão da arrecadação e outra sobre a divisão das despesas entre cinco os diferentes níveis de governo existentes na China; por fim, uma breve aproximação à questão da desigualdade regional a partir da ótica fiscal.

\footnotetext{
${ }^{3}$ MARTINEZ et al., 2014, p. 295.

${ }^{4}$ ASIAN DEVELOPMENT BANK, 2014, p. 101.
} 


\section{O Tax-Sharing System hoje}

Desde então, o sistema implantando em 1994 sofreu grandes modificações, seja na sua estrutura (de vinte e seis impostos para dezoito) ou na repartição entre os níveis de governo (mudança nas alíquotas de repartição dos impostos compartilhados). Os impostos existentes eram os seguintes:

\section{Quadro 01 - Impostos vigentes em 1994}

\begin{tabular}{|c|c|c|c|c|}
\hline $\begin{array}{l}\text { Sobre o } \\
\text { Volume de } \\
\text { Negócios }\end{array}$ & $\begin{array}{c}\text { Tributação } \\
\text { Comum }\end{array}$ & $\begin{array}{l}\text { Imposto Sobre } \\
\text { Renda }\end{array}$ & $\begin{array}{l}\text { Imposto Sobre } \\
\text { Recursos }\end{array}$ & $\begin{array}{l}\text { Imposto Sobre } \\
\text { Propriedade e } \\
\text { Comportamento }\end{array}$ \\
\hline $\begin{array}{l}\text { - VAT (Imposto } \\
\text { Sobre Valor } \\
\text { Adicionado); }\end{array}$ & $\begin{array}{l}\text { - Sobre } \\
\text { Consumo; } \\
\text { - Sobre } \\
\text { Negócios; } \\
\text { - Imposto } \\
\text { aduaneiro; }\end{array}$ & $\begin{array}{l}\text { - Das } \\
\text { empresas; } \\
\text { - Das } \\
\text { empresas } \\
\text { estrangeiras e } \\
\text { com } \\
\text { investimento } \\
\text { estrangeiro; } \\
\text { - Individual; } \\
\text { - Da } \\
\text { agricultura; } \\
\text { - De produtos } \\
\text { agrícolas } \\
\text { especiais; } \\
\text { - De criação } \\
\text { animal; }\end{array}$ & $\begin{array}{l}\text { - Sobre } \\
\text { consumo de } \\
\text { recursos } \\
\text { naturais; } \\
\text { - Sobre uso de } \\
\text { terras urbanas } \\
\text { e municipais; } \\
\text { - Uso de terras } \\
\text { agrícolas; }\end{array}$ & $\begin{array}{l}\text { - Contribuição } \\
\text { predial; } \\
\text { - Sobre } \\
\text { propriedade } \\
\text { Urbana; } \\
\text { - Valorização de } \\
\text { terreno; } \\
\text { - Manutenção e } \\
\text { construção } \\
\text { urbana; } \\
\text { - Sobre selo; } \\
\text { - Sobre escritura; } \\
\text { - Sobre aquisição } \\
\text { de veículos; } \\
\text { - Sobre licença de } \\
\text { veículos e } \\
\text { embarcações; } \\
\text { - Sobre tonelagem } \\
\text { de embarcações; } \\
\text { - Sobre } \\
\text { abatedouros; } \\
\text { - Sobre banquetes; } \\
\text { - Sobre } \\
\text { investimento em } \\
\text { ativos fixos; }\end{array}$ \\
\hline
\end{tabular}

FONTE: ZHU, 2007, p. 96-97. Adaptação e tradução própria.

Em 2004 foi anunciada a diminuição progressiva da carga tributária sobre a agricultura, variando a alíquota e chegando até a eliminação do imposto em algumas províncias $^{5}$. Já em 2006 aboliu-se completamente a tributação sobre a agricultura, encerrando uma prática de 2600 anos na China; além disso, a cobrança sobre criação de animais e abatedouros também foi extinta. Quanto à renda, entre 1999 e 2011 o Comitê Permanente do Congresso Nacional do Povo da República Popular da China fez cinco alterações na cobrança dos indivíduos, principalmente na dedução dos salários e também na cobrança sobre depósitos na poupança. Além disso, unificou o imposto sobre a renda das empresas estatais e estrangeiras, em 
2007, vigorando a partir de 2008; criou a tributação sobre compra de veículos em 2001; e mudou regras de cobrança aduaneira em $2004{ }^{6}$

Incidindo sobre a propriedade, em 2007 o imposto sobre uso de terras urbanas que diferenciava empresas domésticas, estrangeiras e indivíduos foi unificado7, e em 2009 esse foi unificado com a cobrança sobre uso de terras agrícolas. No mesmo ano também se unificou o imposto predial para empresas domésticas, estrangeiras e indivíduos - não os diferenciando também entre chineses e estrangeiros. Incluiu as empresas estrangeiras e com investimento estrangeiro no pagamento do sobre manutenção e construção urbana, em dezembro de 2010. Outros impostos foram instintos, como o sobre investimentos em ativos fixos, que deixou de ser recolhido no ano 2000 e de existir em 2008, assim como o sobre banquetes. ${ }^{8}$ Além disso, houve um esforço muito grande por parte do governo central, a partir de 1997, de limitar o poder de cobranças de multas e tarifas por parte dos governos locais, principalmente de níveis urbanos, eliminando a coleta ilegal. $^{9}$

O Imposto sobre Valor Adicionado (VAT, do inglês Value Added Tax) é o protagonista nesse novo sistema: muitos impostos sobre produtos, com diferentes alíquotas, foram agregados em um só VAT - embora dividido, é controlado pelo governo central, impedindo a desoneração local e uniformizando a cobrança entre as regiões ${ }^{10}$. A partir de 2008 Beijing decidiu transformar a forma de como é orientado, da produção para o consumo e em 2012 iniciou um plano de substituição do Imposto Sobre Negócios pelo VAT. ${ }^{11}$ Em 2013 essa substituição foi expandida para outros setores, chegando, em 2014, aos serviços ferroviários, transportes, correspondências e telecomunicações - chegando à sua efetivação em 2016, quando já alcançava todos os bens e serviços; em 2017 existiam apenas três alíquotas de cobrança, sendo 17\%, 11\% e 6\% - que em 2018 caíram para 16\%, 10\% e $6 \% .^{12}$ Isso tudo fez com que a China chegasse à 2019 com um sistema tributário de apenas dezoito impostos.

\footnotetext{
${ }^{6} \mathrm{JIA}, \mathrm{LI} \& \mathrm{GAO}, 2019$, p. 27-28.

7 STATE TAXATION ADMINISTRATION OF THE PEOPLE'S REPUBLIC OF CHINA, 2019b, p.33.

$8 \mathrm{JIA}, \mathrm{LI} \& \mathrm{GAO}, 2019$, p. 28.

${ }^{9}$ MING \& QUANHOU, 2007, p. 80.

10 NAUGHTON, 2006, p. 434.

11 JIA, LI \& GAO, 2019, p. 27.

12 STATE TAXATION ADMINISTRATION OF THE PEOPLE'S REPUBLIC OF CHINA, 2019b, p.33.
} 


\section{Os Impostos}

Existem basicamente três categorias de tributação que organizam os impostos na China. São elas ${ }^{13}$ :

\section{Bens e Serviços}

-VAT: estão sujeitos todos os que vendem e importam produtos na China, que oferecem serviços de processamento em qualquer nível da cadeia de produção, reparos gerais e instalação de todo tipo, e que ativos intangíveis ou propriedades; as alíquotas podem variar entre 6\% (para serviços de telecomunicações com valor adicionado, financeiros), 9\% (para venda e importação de bens necessários, além de serviços de transporte, postagem, telecomunicações básicas, construção, locação e venda de imóveis e transferência o direito ao uso da terra) e 13\% (vendas e importações de bens gerais, serviços de reparos, processamento e locação de bens móveis) do valor; número de série: um. ${ }^{14}$

- Imposto especial de consumo: tem como objetivo desincentivar a aquisição de 15 categorias específicas de produtos nocivos ou bens luxuosos, como bebidas alcoólicas, cigarros, produtos de beleza, sejam eles produzidos, processados ou importados; a alíquota varia por tipo de produto, podendo ser ad valorem, por unidade ou uma combinação dos dois; número de série: dois.

- Sobre compra de veículos: todos que compram veículos (sujeitos ou entidades) são tributados em $10 \%$ sobre o valor do veículo - carros, motocicletas, bondes, trailers e carregadores agrícolas; número de série: três.

- Aduaneiro: sujeitos que importam, exportar ou trazem de fora bens próprios permitidos pelo governo têm seu produto taxado na fronteira de acordo com a natureza do bem, com alíquotas ad valorem, unitárias ou uma combinação dos dois; número de série: quatro.

\section{Renda}

- Das empresas: todas localizadas dentro do território chinês, tendo sua renda taxada dependendo do seu regimento - se ela é residente, a alíquota é de 25\%; se não é residente (franquias de multinacionais, por exemplo), a alíquota varia entre $20 \%$ e $25 \%$; número de série: cinco.

\footnotetext{
${ }^{13}$ Ibidem, p. 34-38.

${ }^{14}$ WORLDWIDE TAX SUMMARIES, c2020, site.
} 
- Individual: os sujeitos são diferenciados pela sua residência (aqueles que possuem moradia no país ou encontra-se por 183 dias ou mais em um ano fiscalde $1^{\circ}$ de janeiro a 31 de dezembro; ou aqueles que não possuem moradia na China e passaram menos de 183 dias no país durante um ano fiscal) e a fonte de renda: salários e ordenados têm uma alíquota progressiva que varia de $3 \%$ a $45 \%$, sobre a renda anual para residentes e sobre a renda mensal para não residentes ${ }^{15}$; produtores e donos de negócios também são alvo de alíquotas progressivas, variando de $5 \%$ a $35 \%$; autônomos, prestadores de serviços e indivíduos que vivem da renda de royalties, juros, dividendos, empréstimos, venda de propriedades e aluguéis sofrem uma alíquota fixa de $20 \%$ sobre os ganhos. Número de série: seis.

As faixas de renda tributáveis, para cada categoria acima, se dão da seguinte maneira:

Quadro 02 - Alíquotas do Imposto de Renda Individual

\begin{tabular}{|l|c|l|l|l|c|}
\hline $\begin{array}{c}\text { Renda Anual - } \\
\text { Residentes }\end{array}$ & $\begin{array}{c}\text { Alíquota } \\
\text { Aplicada }\end{array}$ & \multicolumn{1}{|c|}{$\begin{array}{c}\text { Renda Anual - } \\
\text { Setor Privado }\end{array}$} & $\begin{array}{c}\text { Alíquota } \\
\text { Aplicada }\end{array}$ & $\begin{array}{c}\text { Renda Mensal - } \\
\text { Não Residentes }\end{array}$ & $\begin{array}{c}\text { Alíquota } \\
\text { Aplicada }\end{array}$ \\
\hline Até $¥ 36.000$ & $3 \%$ & Até $¥ 30.000$ & $5 \%$ & Até $¥ 3.000$ & $3 \%$ \\
\hline Até $¥ 144.000$ & $10 \%$ & Até $¥ 90.000$ & $10 \%$ & Até $¥ 12.000$ & $10 \%$ \\
\hline Até $¥ 300.000$ & $20 \%$ & Até $¥ 300.000$ & $20 \%$ & Até $¥ 25.000$ & $20 \%$ \\
\hline Até $¥ 420.000$ & $25 \%$ & Até $¥ 500.000$ & $30 \%$ & Até $¥ 35.000$ & $25 \%$ \\
\hline Até $¥ 660.000$ & $30 \%$ & Acima de $¥ 500.000$ & $35 \%$ & Até $¥ 55.000$ & $30 \%$ \\
\hline Até $¥ 960.000$ & $35 \%$ & - & - & Até $¥ 80.000$ & $35 \%$ \\
\hline Acima de $¥ 960.000$ & $45 \%$ & - & - & Acima de $¥ 80.000$ & $40 \%$ \\
\hline
\end{tabular}

Fonte: SANTANDER TRADE MARKETS, c2020. Adaptado.

\section{Propriedades e Comportamento}

- Sobre a valorização da terra: todo sujeito que transfere direito de uso de terras estatais que obtém renda dessa transferência dessa transação; a alíquota depende da valorização: até $50 \%$ são tributados $30 \%$; até $100 \%$ são tributados $40 \%$; até $200 \%$ são tributados $50 \%$; e excedendo uma valorização de $200 \%$ são tributados $60 \%$ dessa diferença. ${ }^{16}$ Número de série: sete.

- Sobre imóveis: donos de propriedades nas cidades, municípios, distritos administrativos, e distritos industriais e mineradores têm sua alíquota calculada por duas regras diferentes: para donos que moram na residência, uma alíquota de 1,2\% é aplicada sobre o valor residual (70\% a $90 \%$ do valor pago originalmente); para

\footnotetext{
${ }^{15}$ WORLDWIDE TAX SUMMARIES, c2020, site.

${ }^{16}$ CHINA TAX. Land Apprreciation Tax. c2019. Disponível em: <https://www.china-tax.net/hongkong-and-china-tax/taxation-in-the-prc/land-appreciation-tax.html>. Acesso em: 31/05/2020.
} 
donos que alugam residências, alíquota de $12 \%$ sobre a renda do aluguel. Número de série: oito.

- Sobre uso de terras urbanas e municipais: indivíduos e entidades que utilizam solo urbano pagam um valor fixo sobre o metro quadrado - variando de $¥ 1,5$ a $¥$ 30,00 em cidades grandes; de $¥ 1,2$ a $¥ 24,00$ para cidades médias; de $¥ 0,9$ a $¥$ 18,00 para cidades pequenas; e de $¥ 0,6$ a $¥ 12,00$ para municípios, distritos administrativos, industriais e mineradores. Número de série: nove.

- Sobre uso de terras agrícolas: indivíduos e entidades que usam terras aráveis para construção de casas ou para empreendimentos de usos não agrícolas pagam alíquotas diferenciadas pela localização no território chinês. Número de série: dez.

- Sobre escritura: pago por sujeitos que adquirem ou trocam o direito ao uso da terra ou moradias chinesas - $3 \%$ a $5 \%$ sobre a diferença do valor da propriedade em caso de troca; quando primeira residência, $1 \%$ do valor se tiver até 90 metros quadrados e $1,5 \%$ se for acima dessa metragem; para compradores da segunda casa, $1 \%$ sobre o valor se até 90 metros quadrados e $2 \%$ se acima disso. Essa regra de tributação não é aplicada em Beijing, Shanghai, Guangzhou e Shenzhen. Número de série: onze.

-Sobre consumo de recursos naturais: sujeitos que exploram recursos naturais para extração ou produção de petróleo cru, gás natural, outros minérios não metálicos, minérios ferrosos, não ferrosos, e sal pagam uma alíquota unitária ou ad valorem para cada categoria de recurso. Número de série: doze.

- Sobre licença de veículos e embarcações: proprietários ou manejadores de veículos e embarcações pagam uma quantia fixa dependendo do tipo de transporte. Número de série: treze.

- Sobre selo: expedição ou recebimento de certos documentos determinados sofrem uma cobrança de alíquota fixa ou unitária, dependendo da sua natureza. Número de série: quatorze.

- Manutenção e construção urbana: todos aqueles que são tributados pelo VAT ou pelo Imposto sobre Consumo pagam uma alíquota sobreo valor da primeira contribuição: $7 \%$ para áreas urbanas, 5\% para municípios e distritos, e 1\% para áreas que não sejam categorizadas como urbanas, municipais ou distritais. Número de série: quinze.

- Sobre Tabaco: entidades que compram folhas de tabaco dentro da China pagam uma alíquota fixa de $20 \%$ sobre o valor da transação. Número de série: dezesseis. 
- Sobre tonelagem de embarcações: embarcações que vem do exterior e aportam na China são tributadas pelo seu peso líquido (o total menos o da embarcação em si) em uma quantia fixa por tonelada, diferenciando o valor pelo tipo de produto transportado. Número de série: dezessete.

- De proteção ambiental: todas entidades - empresas, instituições públicas e outros produtores e operadores - que emitem poluição sonora, detritos sólidos, nas águas ou no ar, dentro da China ou em suas regiões jurisdição, são alvo de cobrança de acordo com o nível de poluição que emitem. A alíquota aplicada à cada tipo de degradação e seu nível é especificada pela Lei de Proteção Ambiental. ${ }^{17}$ Número de série: dezoito.

Além disso, o sistema fiscal possui outras duas dimensões que iremos explorar a seguir: a divisão da arrecadação entre os níveis de governo e os gastos orçamentários e também sua divisão entre os níveis de governo.

\section{A Divisão da Arrecadação}

Ao longo dos últimos 25 anos a divisão da arrecadação têm se modificado a favor dos governos locais, mas de maneira contraintuitiva, a participação dos dois governos na receita total se mantém bastante estável, cerca de 50\% pra cada. Arora e Norregaard ${ }^{18}$ apontam os critérios, segundo a teoria econômica tradicional, para alocação de tributos em diferentes níveis de governo: i) a base de arrecadação dos governos locais não pode ser móvel, se não os contribuintes irão se transferir para outra região; ii) se a base de arrecadação foi distribuída homogeneamente pelo território, ela pode ser alvo de tributação dos governos locais, pois isso assegura, teoricamente, uma provisão uniforme de bens e serviços públicos; iii) a correspondência dos impostos pagos e dos bens e serviços oferecidos pelo governo deve ser clara, não permitindo que o fardo tributário seja exportado; iv) os impostos locais devem ser suficientes para suprir o financiamento das despesas do mesmo nível de governo, minimizando desequilíbrios verticais; e v) o princípio do benefício, que cobra dos indivíduos a mesma quantidade de impostos que oferece em serviços públicos, deve guiar a determinação de competências em todos os níveis de governo, mas especificamente no nível local, pois haverá, hipoteticamente, a melhor alocação de recursos possível. Por inferência é possível entender o que determina o tipo de tributo competente ao governo central.

${ }^{18}$ ARORA \& NORREGAARD, 1997. p. 8.
} 
Com o estabelecimento do novo sistema em $1994^{19}$, esses critérios são, de certa forma, respeitados e até mesmo concentrados exageradamente no governo central - isso era esperado, uma vez que um dos objetivos da reforma era exatamente aumentar a participação do governo central na arrecadação total: este então era encarregado das tarifas gerais, o imposto sobre o consumo de bens na alfandega, o de valor adicionado e de renda incidente sobre empresas estatais de controle central, o ainda existente Sobre Negócios - recaindo apenas sobre o setor de ferrovias, bancos e companhias de seguro, e o sobre a renda de instituições financeiras estabelecidas pelo Banco Popular da China; já aos governos locais foi atribuída a arrecadação sobre todos os outros setores do Imposto Sobre Negócios, de renda sobre empresas locais e de indivíduos, e o sobre recursos naturais - além daqueles relacionados a imóveis e terras; divididos entre os níveis de governo eram então o VAT ( $75 \%$ centro; $25 \%$ local) e o sobre o Selo relacionado a seguros $(50 \%$ $50 \%$; relativo a outros assuntos, totalmente local). ${ }^{20}$

Em 2018 a regra para distribuição é a seguinte: para o governo central são destinadas a receita das tarifas em geral; $50 \%$ do VAT, com exceção dos produtos importados que é completamente arrecadado - além da restituição do VAT sobre exportações; de manutenção e construção urbana relacionado a obras do ministério de ferrovias, agências bancárias e de seguros; $60 \%$ do imposto de renda individual e sobre empresas, além de tudo que é arrecadado sobre a renda das empresas de administração central; e tudo o que é arrecadado pelo Imposto Especial sobre Consumo, sobre compra de veículos, sobre tonelagem de embarcações, sobre o selo em transações de seguro e sobre o consumo de recursos naturais na exploração de petróleo offshore. Para os governos locais restam as receitas do imposto de manutenção e construção urbana; tudo que é arrecadado pelo de propriedade de imóveis, uso da terra urbana e da terras agrícolas, valorização da terra, operação de veículos e embarcações, sobre escritura, tabaco, e sobre o uso de recursos onshore; o que sobra do imposto do selo, $50 \%$ do VAT, e $40 \%$ do imposto de renda sobre empresas e indivíduos. ${ }^{21}$

\footnotetext{
${ }^{19}$ MA, 1995, p. 224-225. MING \& QUANHOU, 2007, p. 78.

20 Infelizmente não foram encontrados dados que apurassem a arrecadação por tipo de imposto (para os que existiam) em 1994, nem sua divisão entre os níveis central local - essa última informação só começa a aparecer nos anuários estatísticos chineses a partir de 2003 (com dados de 2002). O que se sabe é que a divisão da arrecadação total para aquele ano foi de $56 \%$ para o governo central e $44 \%$ para o local.

${ }^{21}$ NATIONAL BUREAU OF STATISTICS OF CHINA, 2019.
} 
Os impostos mais importantes para a arrecadação como um todo são o VAT $(42,41 \%)$, seguido do imposto de renda das empresas $(19,26 \%)$ e individual $(7,57 \%)$, correspondendo a mais de dois terços de toda a receita do governo chinês $(69,24 \%)$. Para o governo central o VAT e a renda das empresas também são muito importantes, correspondendo a $81 \%$ de toda sua arrecadação, seguidos imediatamente pelo imposto especial sobre consumo (12,44\%) e a renda individual (9, 74\%) - quando se consideram as restituições do VAT devida a exportadores, a participação desse imposto ainda é de $36 \%$ do total recebido pelo governo central. Para os governos locais a situação não é diferente: o VAT continua sendo o mais importante (31,44\%), e a contribuição sobre a renda das empresas também $(13,36 \%)$, mas como não the compete arrecadar sobre o consumo especial, os próximos mais importantes são os relacionados ao seu território - sobre escritura, valorização da terra, de manutenção e construção urbana, propriedade de imóveis, uso da terra urbana e agrícola, e sobre recursos naturais somam $24,75 \%$ de todas as suas receitas.

Fica evidente a importância da Receita Não Tributária no orçamento dos governos locais $(22,42 \%)$ e também no governo central $(5,86 \%)$. Nos dados disponíveis, podemos ver que ela compõe, desde 1950, uma média de $29 \%$ da arrecadação total, com uma variação enorme durante esses anos - como pode ser visto na figura 14 abaixo, há um pico de 64,41\% em 1960 e um mínimo de -2,35\% em 1989. Essa receita se divide em duas categorias: as extraorçamentárias (ExtraBudgetary Revenues - EBR), compostas por fundos governamentais e sobretaxação, fundos especiais para as empresas estatais e fundos de arrecadação própria dos governos locais; e as não orçamentárias (Off-Budgetary Revenues $O B R$ ), compostas por contribuições voluntárias de indivíduos, empresas ou chineses no exterior, cobrança de taxas e multas, lucro das Empresas de Povoado e Cantão, e da venda de terras ${ }^{22}$.

Segundo Brys $^{23}$, a China tem maior participação das receitas não tributárias na receita total do que os países da OCDE - em 2009 existiam 34 fundos governamentais e 236 tipos de taxas administrativas, além das cobranças por parte dos governos locais e as contribuições para a seguridade social. Existem poucos dados relativos a divisão entre o governo central e os locais dessa receita, mas é possível perceber que desde 2002 a participação na renda total tem aumentado de

23 BRYS et al., 2013, p. 6.
} 
$1,5 \%$ no governo central e $13 \%$ nos locais para $5,9 \%$ e $22,4 \%$, respectivamente, em $2018^{24}$. Durante esse período, tanto a parcela que compõe a receita total de cada nível de governo quanto o volume dessa receita foi maior para os governos locais na verdade, essa contrapartida na pouca discricionariedade tributária vem da época dos contratos do Fiscal Responsability System; os fundos que os governos locais mantinham eram seus resguardos das remessas devidas ao governo central, já que não eram divididos ou reportados; essas receitas normalmente são usadas para cobrir os déficits orçamentários e financiar projetos locais, já que estes não são autorizados a fazer empréstimos; o governo central tenta controlar essa receita de duas maneiras: regulamenta as taxas que os governos locais podem cobrar e cobra delas um relatório de arrecadação dessas taxas, além das receitas ganhas com transferências de terras ${ }^{25}$.

Para o ano de 2018 81\% de toda receita não tributária era de responsabilidade dos governos locais: as principais fontes foram os fundos para programas especiais, os quais recebem transferências do governo central para políticas com objetivos específicos; renda vinda do uso dos ativos estatais (principalmente terras) e a cobrança de taxas e multas. Já para o governo central, a fonte de $64,3 \%$ de toda receita não tributária foram as Operações de Capital.

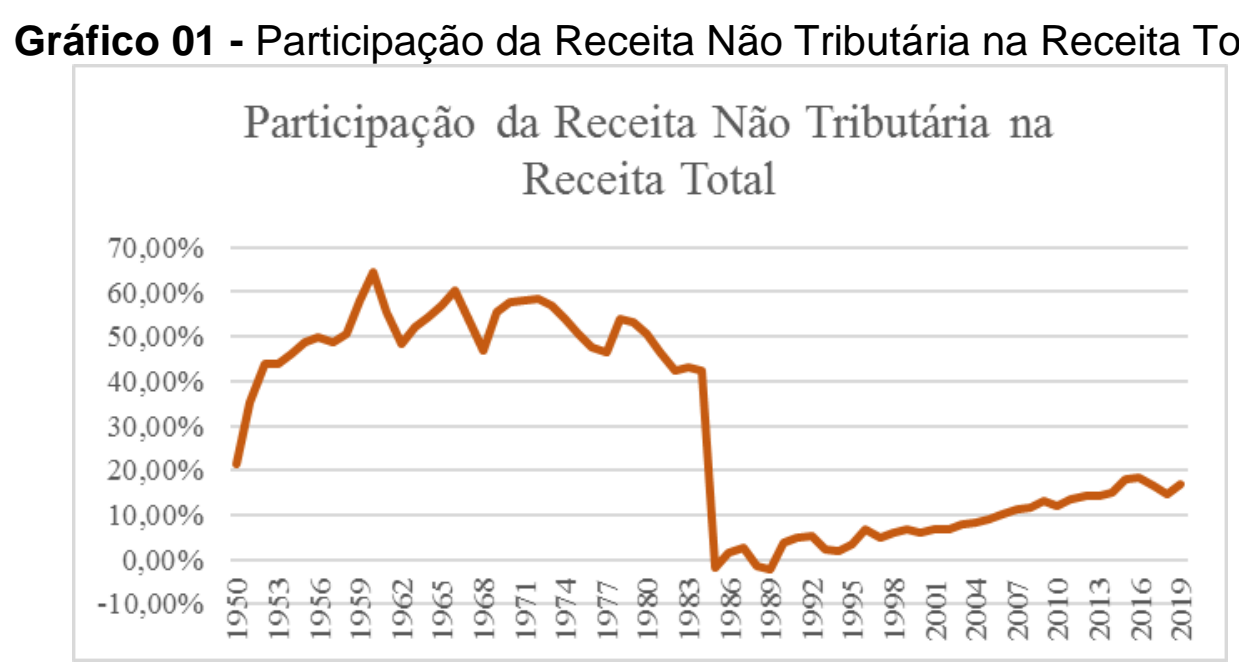

FONTE: National Bureau of Statistics of China. Elaboração própria.

De maneira geral, podemos perceber que mesmo com as mudanças nos impostos e nas suas divisões entre os diferentes níveis de governo, a divisão centro/localidades permaneceu bastante estável durante esses vinte e cinco anos:

\footnotetext{
${ }^{24}$ National Bureau Of Statistics Of China, site.

${ }^{25}$ MING \& QUANHOU, 2007, p. 91.
} 
em média $51 \%$ foi destinado ao governo central e $49 \%$ aos locais, como pode ser visto abaixo. A única consideração que deve ser feita é que como o governo central recolhe tanto os seus impostos quanto os que divide, não deixa margem para desonerações ilegais por parte dos governos locais: $87,81 \%$ de tudo que é arrecadado (tudo que é receita tributária) é recolhido pelo governo central $(77,63 \%$ se consideradas as restituições).

\section{A Divisão das Despesas}

Antes da reforma de 1994, o governo central era responsável por investimentos em infraestrutura, aprimoramento tecnológico das empresas estatais sob seu controle, pesquisa e desenvolvimento, universidades e institutos de pesquisa, administração de instituições nacionais - como o sistema judiciário, defesa nacional, assistência e relações internacionais, conservação da agricultura, florestas e águas a nível central, operações industriais, comerciais e de transporte, educação, cultura, saúde e serviços sociais, subsídio de preços instituído pelo próprio governo central, levantamentos geológicos, e financiamento do débito público; os subnacionais encarregavam-se da construção básica, investimentos em estatais sob seu controle, desenvolvimento e assistência agrícola, conservação de águas, manutenção e construção urbana, educação, saúde, cultura e serviços socais, segurança pública, seguridade social e pensões, gastos administrativos, e uma variedade de subsídios à preços. ${ }^{26}$

Aqui pode se aplicar também o princípio do benefício para alocar as despesas entre os diferentes níveis de governo: a manutenção de vias públicas e transportes, saneamento e educação básicos para níveis locais; educação secundária, proteção ambiental e provisão de saúde especializa para níveis regionais; e políticas de estabilização macroeconômica a cargo do governo - novamente baseado na teoria econômica mais tradicional, esse princípio é fundamentado por conceitos como economia de escala, efeitos transbordamento, freeriders, externalidades positivas e negativas. Como pôde ser visto, a divisão do gasto público chinês confere, de certa forma, com essas diretrizes - na verdade, essa distribuição de poderes tem se mantido bastante estável nos últimos quarenta anos. ${ }^{27}$

No período de 1994 a 2019 o gasto público teve seu valor nominal aumentado em mais de quarenta vezes $(¥ 5.792,62$ - $¥ 238.874,02$; valores em 100 milhões de

\footnotetext{
${ }^{26}$ MA, 1995, p. 211. WONG, 2000, p. 4.

${ }^{27}$ ARORA \& NORREGAARD, 1997. p. 6-7, 13-14, 19.
} 
yuans) e a proporção com relação ao PIB mais que dobrou (de 11,91\% para 24,11\%). Além disso, há uma tendência a descentralização também: em 19940 governo central era responsável por 30\% dos gastos totais, enquanto em 2019 foi menos que $15 \%$ - isso se dá graças ao aumento dos gastos a níveis subnacionais, principalmente em seguridade social (seguros desemprego, aposentadorias, subsídios para habitação e preços em geral), e com o aumento dos salários a prestação de serviços também ficou mais cara ${ }^{28}$.

Há essa contradição (aumento da participação dos governos locais no gasto público total, mas com divisão de competências) não só por causa da melhoria de vida da população - com expectativa de vida melhor e aumento dos salários, existem mais pessoas a oferecer serviços públicos no geral, mas porque existe uma sobreposição dessas competências: pelo menos desde 1978 não existem regras que delimitem estritamente a atuação de cada nível de governo, tanto que muitos setores (têm investimentos cofinanciados pelos governos locais (tanto provinciais quanto mais baixos) ${ }^{29}$.

$\mathrm{Na}$ verdade, para níveis subprovinciais não existem regras estabelecidas: cada província estipula com seus níveis inferiores a distribuição dos gastos dentro de seu território ${ }^{30}$; em 2002 e 2005 foram sugeridas diretrizes para guiar a alocação das despesas nos níveis subprovinciais - i) a divisão clara de responsabilidade de gasto entre os condados e vilarejos, ii) o aprimoramento da estrutura de governo dos vilarejos e controle dos funcionários públicos empregados; iii) monitoramento dos riscos fiscais desses níveis; e iv) (em 2005) aumentar o monitoramento na performance do sistema de gastos. A relação entre os condados e vilarejos tem os primeiros determinando os gastos dos segundos, mas os condados têm relações diretas tanto com as cidades/prefeituras acima deles quanto com as próprias províncias: no primeiro caso as prefeituras podem estabelecer responsabilidades tanto de gasto quanto de arrecadação, transferências e subsídios; no segundo, as províncias mantém as mesmas relações com os condados, sem intermediação das prefeituras (na verdade, não existem relações diretas entre prefeituras e condados nesse modelo) - adotam essa organização as províncias de Zhejinag, Anhui, Hubei,

\footnotetext{
${ }^{28}$ WONG, 2000, p. 6.

${ }^{29}$ MA, 1995, p. 211-212.

${ }^{30}$ JIA, GUO \& ZHANG, 2014, p. 110.
} 
Hailongjiang, Fujian, Hainan e Ningxia, e as cidades de Beijing, Shanghai, Tiajin e Chongqing. ${ }^{31}$

Quadro 03 - Atribuição de despesas por nível administrativo

\begin{tabular}{|c|c|c|c|c|c|}
\hline Função & Central & Provincial & Prefeituras & Condados & Vilarejos \\
\hline Defesa Nacional & $\mathrm{x}$ & & & & \\
\hline Relações Exteriores & $\mathrm{x}$ & & & & \\
\hline Prospecção Geológica & $\mathrm{x}$ & & & & \\
\hline Dívida Pública & $\mathrm{x}$ & & & & \\
\hline Educação & $x$ & $\mathrm{x}$ & $x$ & $\mathrm{x}$ & $x$ \\
\hline Saúde & $\mathrm{x}$ & $\mathrm{x}$ & $\mathrm{x}$ & $\mathrm{x}$ & $\mathrm{x}$ \\
\hline Bem Estar Social & $\mathrm{x}$ & $\mathrm{x}$ & $\mathrm{x}$ & $\mathrm{x}$ & $\mathrm{x}$ \\
\hline Agricultura & $\mathrm{x}$ & $\mathrm{x}$ & $\mathrm{x}$ & $\mathrm{x}$ & $\mathrm{x}$ \\
\hline Administração do Governo & $\mathrm{x}$ & $\mathrm{x}$ & $\mathrm{x}$ & $\mathrm{x}$ & $\mathrm{x}$ \\
\hline Construção em Infraestrutura & $\mathrm{x}$ & $\mathrm{x}$ & $\mathrm{x}$ & $\mathrm{x}$ & $\mathrm{x}$ \\
\hline Pesquisa e Desenvolvimento & $x$ & $x$ & $x$ & $\mathrm{x}$ & $x$ \\
\hline Cultura e Entretenimento & $\mathrm{x}$ & $\mathrm{x}$ & $\mathrm{x}$ & $\mathrm{x}$ & $\mathrm{x}$ \\
\hline Subsídios & $\mathrm{x}$ & $x$ & $x$ & $x$ & $\mathrm{x}$ \\
\hline Tropas Policiais & $\mathrm{x}$ & $\mathrm{x}$ & $\mathrm{x}$ & $\mathrm{x}$ & $\mathrm{x}$ \\
\hline Manutenção e Construção Urbana & & $\mathrm{x}$ & $\mathrm{x}$ & $\mathrm{x}$ & $x$ \\
\hline Proteção Ambiental & & $\mathrm{x}$ & $\mathrm{x}$ & $x$ & $\mathrm{x}$ \\
\hline Saneamento & & & $\mathrm{x}$ & $\mathrm{x}$ & $x$ \\
\hline Serviços Comunitários & & & & $x$ & $\mathrm{x}$ \\
\hline
\end{tabular}

Fonte: SHEN, JIN \& ZOU, 2012, p. 17

A partir de Martinez ${ }^{32}$, a relação de cada nível de governo com as maiores despesas públicas na China é a seguinte:

- Educação: para a educação básica, o papel do governo central é regulamentar, estabelecer diretrizes e metas - além de criar fundos para subsidiar a educação básica em regiões mais pobres; aos governos provinciais cabe definir um plano de desenvolvimento dessas políticas e auxiliar financeiramente os condados a alcançarem os gastos necessários com educação; são os governos locais (prefeituras, cidades) que financiam e implementam a educação básica (no caso rural, são os condados). Já para os níveis mais altos de educação, o gasto é compartilhado: o governo central também detém o poder de regulamentar o ensino, mas financia diretamente suas instituições, assim como os governos provinciais.

-Saúde: as atribuições são semelhantes à da educação - o governo central estipula políticas, diretrizes e metas, os governos provinciais planejam as políticas e os níveis mais baixos as implementam. Mas, para o caso de áreas rurais o governo central tem atuado como planejador dessas políticas, enquanto as províncias estipulam a implementação e os níveis mais baixos apenas acatam essas decisões.

\footnotetext{
${ }^{31}$ ASIAN DEVELOPMENT BANK, 2014, p. 111-113.

32 MARTINEZ et al., 2014, p. 305-308.
} 
- Seguridade Social: boa parte dos benefícios pagos à população são de responsabilidade dos governos subnacionais - delegados a governos provinciais e prefeituras, uma vez que nos condados a população é rural e não se encaixam nos programas de aposentadoria e pensão.

- Infraestrutura: como dito anteriormente, é uma categoria de despesa bastante dividida entre os diferentes níveis de governo - existe apenas uma hierarquia evidente no nível de gastos por nível de governo subnacional: os mais altos são os que mais gastam.

- Desenvolvimento agrícola: é responsabilidade do governo central serviços operacionais e de produção agrícola, implementando políticas para aumentar o nível geral de investimentos. Aos governos locais cabe a implantação de políticas gerais, também de conservação dos campos agrícolas, florestas e águas; é quem financia também pesquisa e desenvolvimento na área.

Quando observamos o esclarecimento no próprio anuário estatístico chinês mais recente ${ }^{33}$, percebemos a ligeira explicação da determinação dos gastos em cada nível de governo:

\footnotetext{
"The general public expenditure of the Central Government includes the expenditure for general public services, expenditure for foreign affairs, expenditure for public security, and the general public budget expenditure of the Central Government for adjusting the national economic structure; coordinating the development among different regions; and exercising macroeconomic regulation. The general public budget expenditure of the local governments includes mainly the expenditure for general public services, expenditure for public security, and expenditures for social development which are planed by local governments, etc."
}

Observando os dados para 2018, percebemos que os maiores gastos são com educação (14,6\%), seguridade social e emprego (12,2\%), assuntos comunitário urbanos e rurais (10\%) e conservação da agricultura, florestas e águas $(9,5 \%)$ todos esses correspondem a quase metade dos gastos totais $(46,35 \%)$. Para o governo central, mais da metade $(56,1 \%)$ é gasto com defesa nacional, pagamento de juros e investimento em ciência e tecnologia; para os governos locais, os gastos estão melhor divididos entre educação (16\%), seguridade social e emprego $(13,7 \%)$, assuntos comunitários urbanos e rurais $(11,7 \%)$, conservação da agricultura, florestas e águas (10,9\%), serviços públicos gerais (9\%) e cuidados médicos, de saúde e planejamento familiar $(8,19 \%)$.

\section{A Questão Regional}

${ }^{33}$ NATIONAL BUREAU OF STATISTICS OF CHINA, 2019. 
Quando observamos a distribuição dessas variáveis ao longo do território chinês, percebemos o desequilíbrio regional latente: é na verdade uma questão histórica que se arrasta por muito tempo - a costa leste desenvolvida e a região norte e oeste economicamente atrasadas. Como podemos ver abaixo, as regiões mais ricas são a Leste e a Centro-Sul ( $¥ 345.737,73$ e $¥$ 246.310,52, respectivamente, em 2018 e em 100 milhões de yuans), enquanto as regiões Norte, Sudoeste, Nordeste e Noroeste são mais debilitadas ( $¥ 119.247$,22, $¥ 95206,52$, $¥$ 56751,59 e $¥ 51.453$,88, respectivamente, em 2018 e em 100 milhões de yuans).

Quando observamos também o nível de receita, tanto geral quanto per capita ou como proporção do PIB de cada uma delas, dissipa-se um pouco a desigualdade com relação as regiões de minorias étnicas (Mongólia Interior, Tibete, etc.) por sua população ser pequena, e também seu PIB - o Tibete, por exemplo, têm uma alta participação da receita em seu PIB (15,59\%, quando a média é $11,12 \%)$, mas os menores números tanto em receita quanto PIB. As únicas regiões que sempre se destacam são Beijing e Shanghai - embora não tenham os valores nominais mais altos, lideram quando observados relativamente à população e ao PIB.

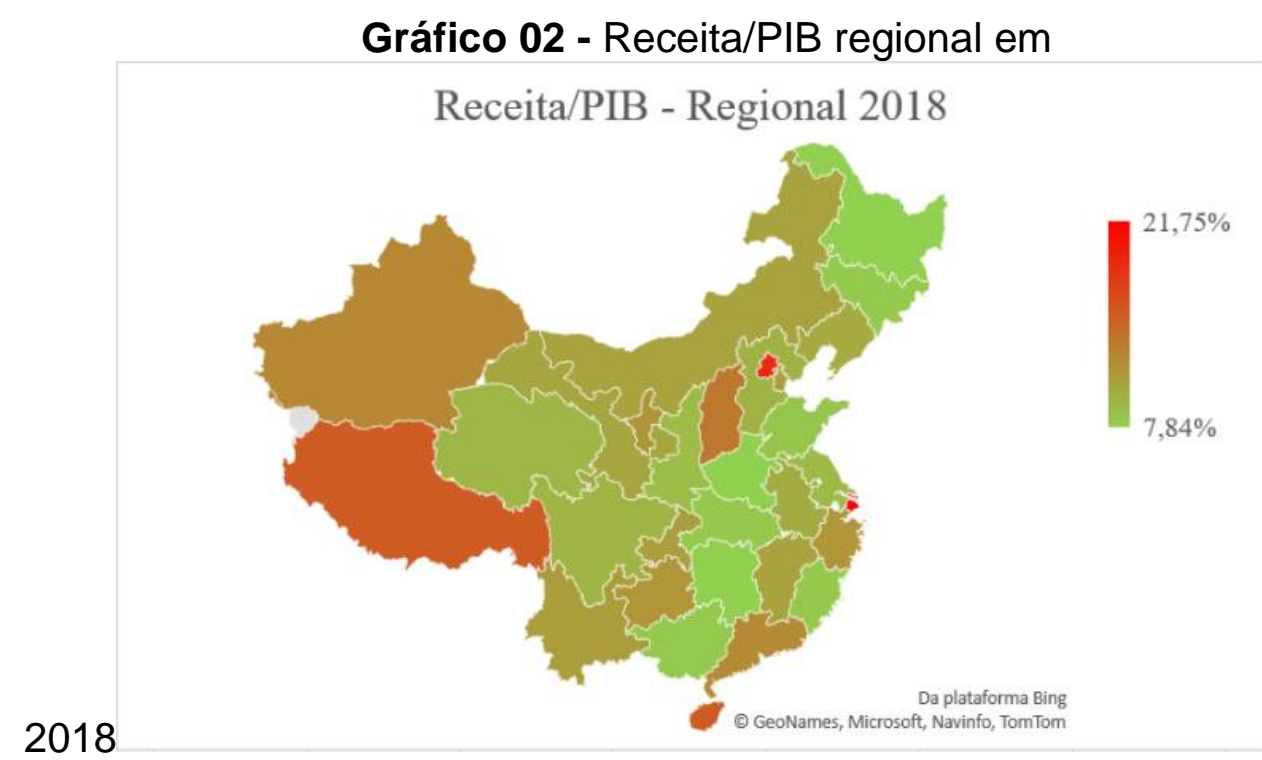

Fonte: National Bureau of Statistics of China. Elaboração própria. 


\section{Gráfico 03 - Receita per capita regional em}

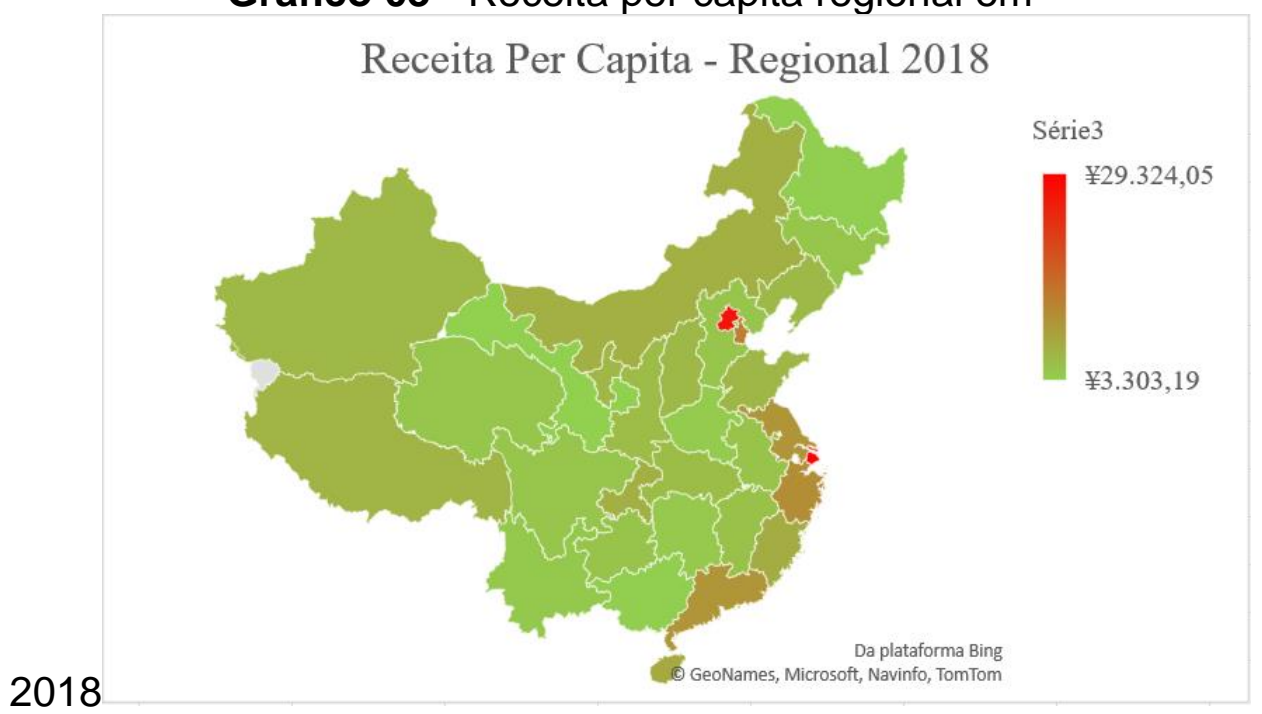

Fonte: National Bureau of Statistics of China. Elaboração própria.

Diante dessa desigualdade, existe tanto no novo modelo de organização fiscal, quanto nos anteriores, um sistema de transferências para amenizar essa desigualdade e equalizar o nível de despesas públicas interprovinciais. A principal inovação do Tax-Sharing System é a existência de regras para transferências ${ }^{34}$ : até então, como foi dito anteriormente, as transferências eram negociadas entre 0 governo central e com cada província isoladamente. São três marcos importantes que fundamentam esse novo sistema de transferências: o primeiro é o esquema de restituição tributária em 1994, sobre o consumo e VAT, do governo central para as províncias - dessa forma, compensaria a perda de receitas diretas proporcionada pela reforma; em 1995 foi estabelecida uma regra de transferências de acordo com a necessidade de cada província (déficit local), a capacidade de transferência do governo central (a renda destinada para essas transferências), e as transferências com objetivos específicos, que aumentaram significativamente de volume a partir de 1999. ${ }^{35}$ Além disso, existem também as transferências obrigatórias, definidas pela divisão da arrecadação - isto é, como a arrecadação é dividida com o governo central e é este quem recolhe todo o montante, precisa, em seguida, fazer os repasses devidos aos governos subnacionais. No detalhe:

- A regra de restituição é simples - a transferência desse ano é a do ano anterior aumentada em $30 \%$ da variação do imposto sobre o consumo e $75 \%$ do VAT também com relação ao ano anterior. Algebricamente ${ }^{36}$ :

\footnotetext{
${ }^{34}$ MARTINEZ et. al., 2014, p. 335.

${ }^{35}$ MING \& QUANHOU, 2007, p. 83-86.

${ }^{36}$ HUANG \& CHEN, 2012, p. 537.
} 


$$
\mathrm{TR}_{\mathrm{i}, \mathrm{t}}=\mathrm{TR}_{\mathrm{i}, \mathrm{t}-1} \cdot\left[1+0,3 * \frac{\left(\mathrm{CT}+0,75 \mathrm{VAT}^{\mathrm{i}, \mathrm{t}}-(\mathrm{CT}+0,75 \mathrm{VAT})_{\mathrm{i}, \mathrm{t}-1}\right]}{\left(\mathrm{CT}+0,75 \mathrm{VAT}_{\mathrm{i}, \mathrm{t}-1}\right.}\right]
$$

Onde CT é o imposto sobre consumo, e TR $\mathrm{R}_{\mathrm{i}, \mathrm{t}} \mathrm{O}$ volume de transferências de restituição para a província i no tempo t. Como podemos perceber, é uma distribuição regressiva das transferências, uma vez que as províncias que mais recebem são as mais economicamente desenvolvidas, pois são as que arrecadam mais.

- As transferências de acordo com a necessidade, ou regra de equalização, também é bem clara - a transferência direcionada a província escolhida é dada pela participação do déficit local no nacional vezes a dotação destinada a isso. Algebricamente 37 :

$$
T E_{i}=D D * \frac{D T_{i}-R T_{i}}{D T-R T}
$$

Onde TE é a transferência equalizadora, com relação a província i, DT a despesa total nacional, e RT a receita total nacional. A partir dessa regra, notamos que apenas as províncias ou regiões que entram em déficit são aquelas que recebem transferências do governo central.

- Transferências com objetivos específicos podem ser divididas em duas categorias: aquelas direcionadas a complementar os orçamentos das localidades, para que possam alcançar os níveis de gasto exigidos pelo governo central; e aquelas que financiam projetos determinados. No primeiro caso, o objeto é diminuir o desequilíbrio vertical entre os níveis de governo, possibilitando maior alocação de recursos pelos governos locais - por exemplo, visando regiões agrícolas, de minorias étnicas, ou aumento de salário dos funcionários públicos, entre outros. Já no segundo, o financiamento é direcionado a programas de desenvolvimento agrícola, de suporte ao investimento em infraestrutura, e até para compor fundos de reestruturação após catástrofes naturais. ${ }^{38}$

Como dados de transferências não estão disponíveis, nem por região, nem por categoria de remessas, podemos especular o nível dessa realocação de recursos a partir das contas do governo central, do déficit nacional, e do déficit regional e como ele se distribui pelo território chinês, tanto na dimensão per capita quanto com relação ao PIB de cada localidade. Para o ano de 2018, as contas

\footnotetext{
${ }^{37}$ Ibidem, p. 538.

${ }^{38}$ ASIAN DEVELOPMENT BANK, 2014, p. 115-199. SHEN, JIN \& ZOU, 2012, p. 21-23.
} 
nacionais na relação arrecadação/gasto fecharam em um déficit de $¥ 37.544,29$ (em 100 milhões de yuan), o governo central apresentou um superávit de $¥ 52.748,65$ (em 100 milhões de yuan), e a soma dos governos locais proporcionou um déficit de $¥ 90.292,94$ (em 100 milhões de yuan), onde todas as regiões foram deficitárias.

Quando analisamos graficamente o padrão de distribuição desse déficit, ele confirma o da distribuição das receitas: as regiões que arrecadam menos são as mais deficitárias, pois são aquelas que só conseguem financiar sua despesa a partir das transferências. Nessa noção, o déficit guia as transferências, esperando que com essas seja possível não cessar o déficit, mas amezinhar as diferenças regionais - as transferências não existem puramente para fechar um regime de contas, mas para desenvolver as regiões desfavorecidas. Por isso que uma análise déficit/PIB e déficit per capta se torna mais parecida com o padrão de mesma distribuição dos gastos.

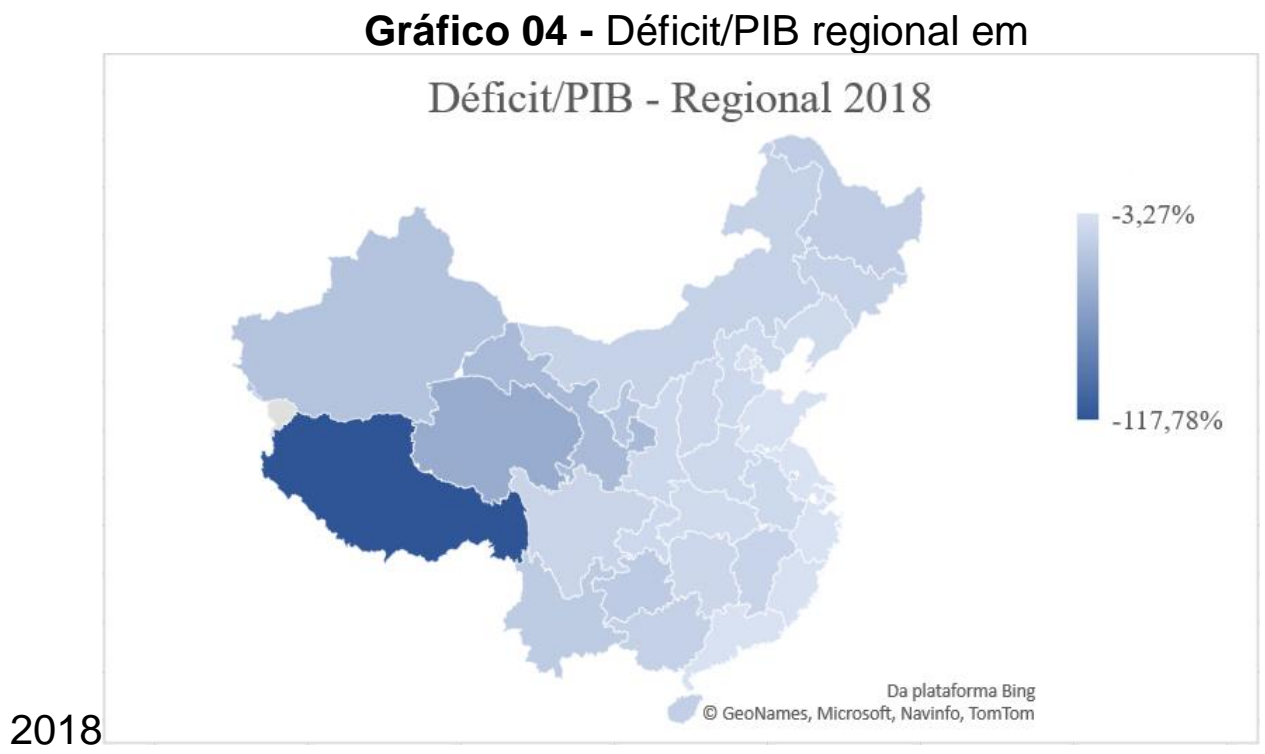

Fonte: National Bureau of Statistics of China. Elaboração própria. 


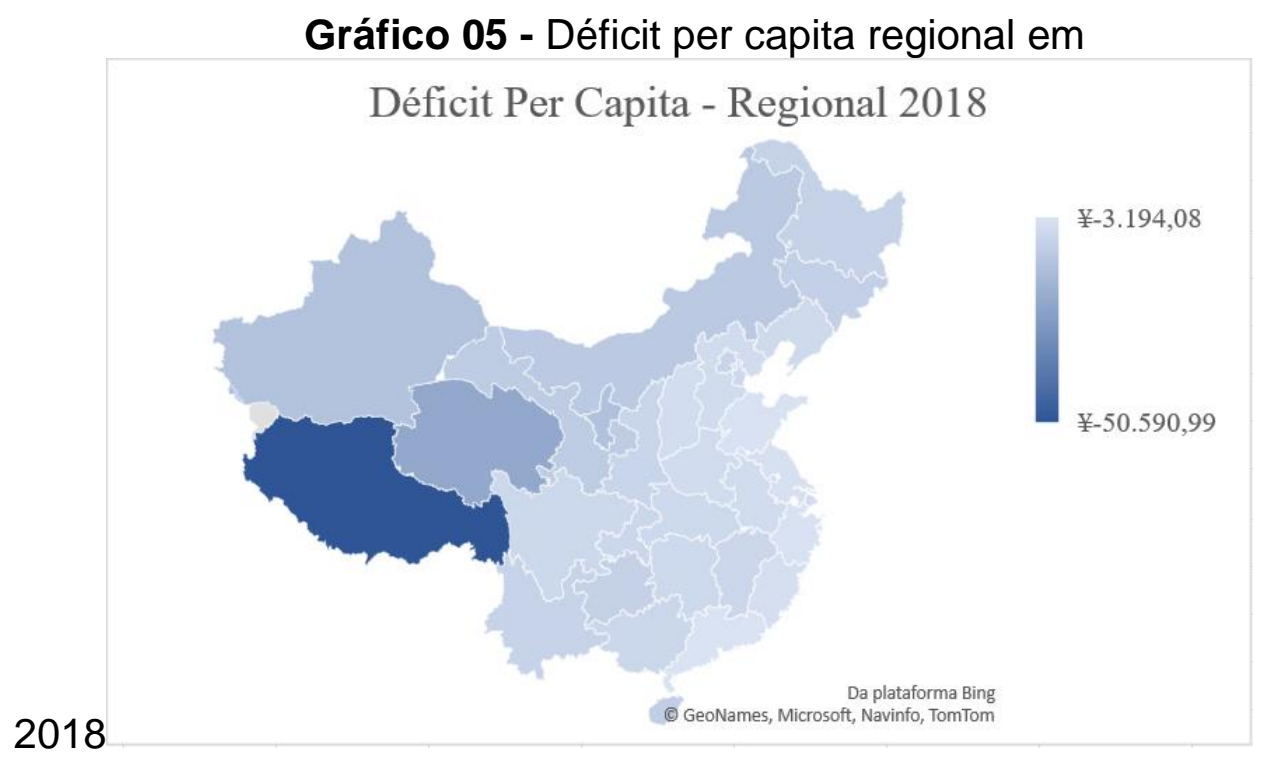

Fonte: National Bureau of Statistics of China. Elaboração própria.

Assim, podemos observar como se distribui o gasto orçamentário pelo território chinês. As regiões que apresentam as maiores receitas também são as que apresentam maior nível de despesas: a Leste e a Centro-Sul ( $¥ 55.811,74$ e $¥$ 46.686,91, respectivamente e em 100 milhões de yuans); seguidas pelas Norte, Sudoeste, Noroeste e Nordeste ( $¥ 27.416,17$, $¥ 27323,84,17.153,61$ e $¥ 13.804,06$, respectivamente e em 100 milhões de yuans). Mas quando analisamos a partir do PIB e da população, a lógica da distribuição da receita se inverte: o Tibete, por exemplo, é o destaque pelos maiores indicadores (133\% do PIB e ¥57.287,21 per capita). Graficamente:

Gráfico 06 - Despesa/PIB regional em

Despesas/PIB - Regional 2018

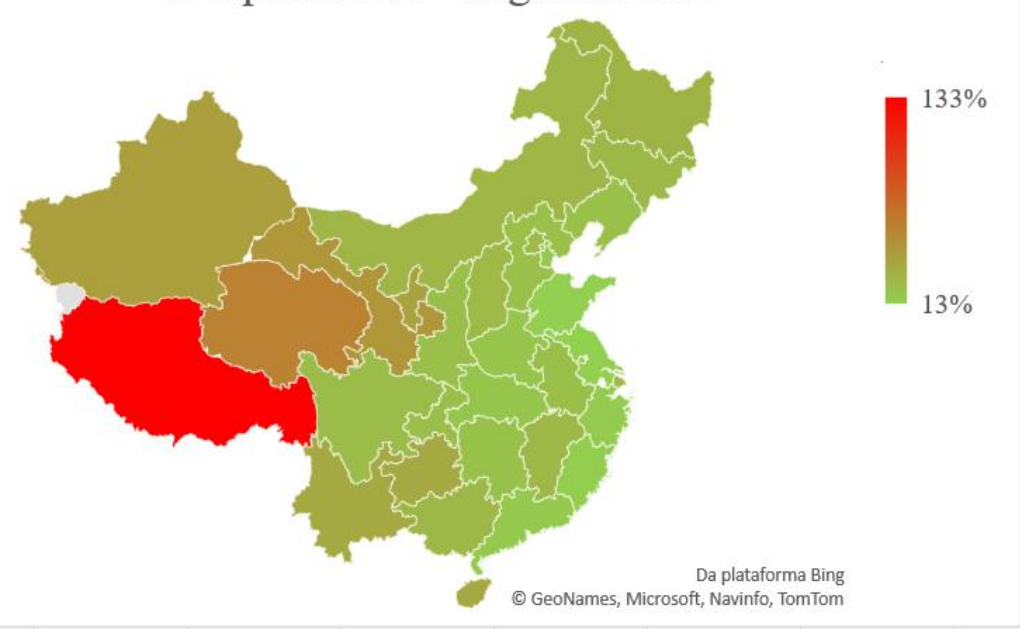

2018

Fonte: National Bureau of Statistics of China. Elaboração própria. 


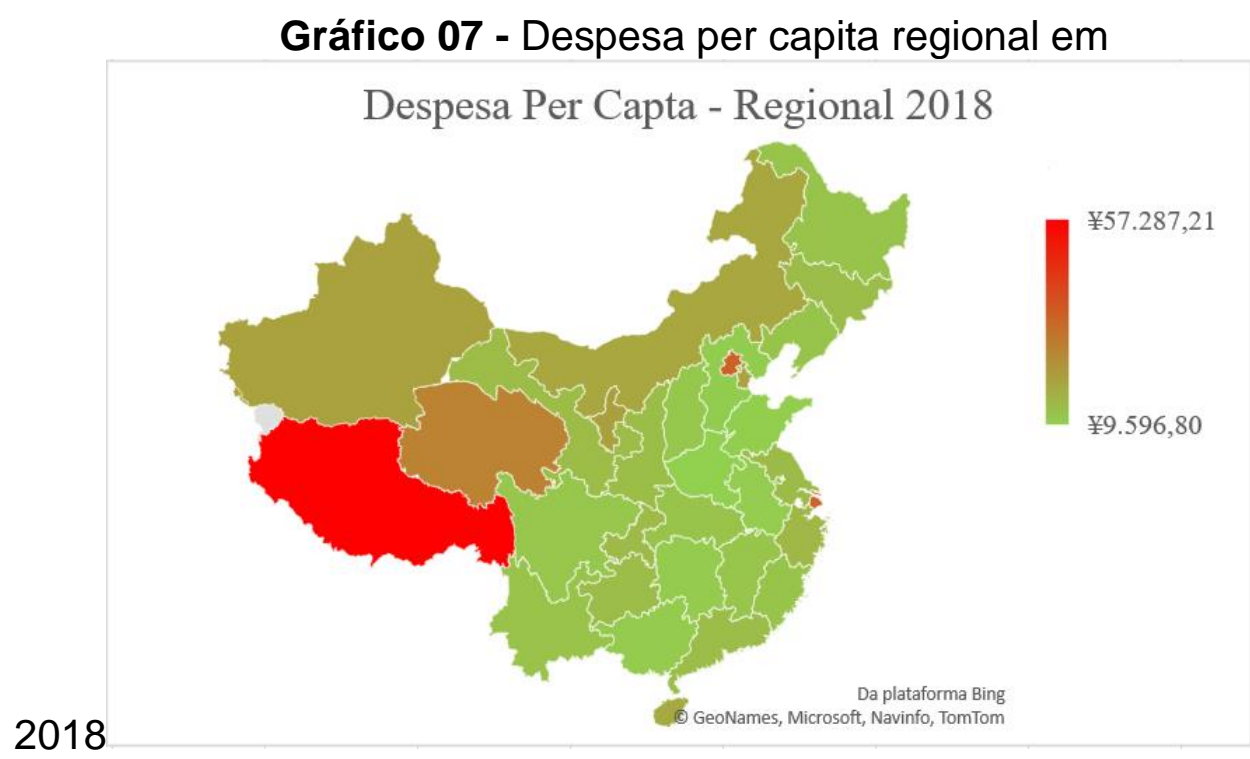

Fonte: National Bureau of Statistics of China. Elaboração própria.

\section{Considerações Finais}

Esse trabalho teve como objetivo apresentar o funcionamento e a organização do sistema fiscal chinês. Algumas considerações precisam ser destacadas: na China, apenas $15 \%$ do gasto público total corresponde ao executado pelo governo central, enquanto $85 \%$ são responsabilidade dos governos provinciais e subprovinciais; a equalização fiscal é guiada pelo déficit regional, diferente de outros países, como o Brasil, que concebem regras arbitrárias para transferências de equalização; além disso, o orçamento público financia basicamente gastos em bens e serviços sociais, enquanto cabe ao setor financeiro $o$ financiamento do investimento público. Segundo dados apurados a partir das bases de dados apresentadas, durante os últimos 70 anos a China foi um país descentralizado, isto é, os governos subnacionais foram responsáveis por mais da metade da arrecadação e dos gastos.

Esta pesquisa faz parte de um esforço maior de investigação do sistema fiscal chinês e as relações fiscais entre os diferentes níveis de governo - este artigo é a adaptação de um capítulo da dissertação a ser apresentada para obtenção do título de mestre, no Programa de Pós-Graduação em Políticas Públicas da Universidade Federal do Paraná, pelo aluno Jaderson Goulart Junior, sob orientação do professor dr. Demian Castro.

\section{REFERÊNCIAS}


ARORA, Vivek B.; NORREGAARD, John. Intergovernmental fiscal relations: the Chinese system in perspective. International Monetary Fund, Asia and Pacific Department and Fiscal Affairs Department, 1997.

ASIAN DEVELOPMENT BANK.Money Matters: local government finance in the People's Republic of China. Mandaluyong City (Philippines), 2014. 148 p.

BRYS, Bert et al. Tax Policy and Tax Reform in the People's Republic of China. OECD Taxation Working Papers, n. 18, 2013. 63 p.

CHINA BRIEFING. China's Environmental Protection Tax. 18 de janeiro de 2018.

Disponível em? < https://www.china-briefing.com/news/china-environmental-protection-tax/>. Acesso em: 01/06/2020.

HUANG, Bihong; CHEN, Kang. Are intergovernmental transfers in China equalizing?. China Economic Review, v. 23, n. 3, p. 534-551, 2012.

JIA, Jierui; LI, Junyang; GAO, Ke. A Brief Discussion on the Changes of Tax System Since China's Reform and Opening up (1978-2018). American Journal of Management Science and Engineering, v. 4, n. 2, p. 26, 2019.

MA, Jun. The reform of intergovernmental fiscal relations in China. Asian Economic Journal, v. 9, n. 3, p. 205-232, 1995.

MARTINEZ, Jorge et al. An essay on public finance in china. Annals of Economics and Finance, v. 15, n. 1, p. 289-405, 2014.

MING, Su; QUANHOU, Zhao. China: fiscal framework and urban infrastructure finance. In: PETERSON, George E.; ANNEZ, Patricia Clarke (Ed.). Financing cities: fiscal responsibility and urban infrastructure in Brazil, China, India, Poland and South Africa. Sage, 2007. pp. 74-107.

NAUGHTON, Barry J. The Chinese economy: Transitions and growth. Cambridge, Massachusetts: MIT press, 2006.

NATIONAL BUREAU OF STATISTICS OF CHINA. China Statistical Yearbook - 2018. Distrito de Fengtai, Pequim: 2018. Disponível em:

http://www.stats.gov.cn/tjsj/ndsj/2018/indexeh.htm.

NATIONAL BUREAU OF STATISTICS OF CHINA. China Statistical Yearbook - 2019. Distrito de Fengtai, Pequim: 2019. Disponível em:

http://www.stats.gov.cn/tjsj/ndsj/2019/indexeh.htm.

REPÚBLICA POPULAR DA CHINA, Constituição da República Popular da China. Distrito de Xicheng, Pequim: Quinta Assembleia Popular Nacional. Disponível em:

https://bo.io.gov.mo/bo/i/1999/constituicao/index.asp\#1999. Acesso em: 25 de fevereiro de 2020.

SANTANDER TRADE MARKETS. China: Tax System. Maio de 2020. Disponível em: < https://santandertrade.com/en/portal/establish-overseas/china/tax-system>. Acesso em: 31/05/2020.

SHEN, Chunli; JIN, Jing; ZOU, Heng-fu. Fiscal decentralization in China: history, impact, challenges and next steps. Annals of economics and finance, v. 13, n. 1, p. 1-51, 2012.

STATE TAXATION ADMINISTRATION OF THE PEOPLE'S REPUBLIC OF CHINA. Tax System. c2019. Disponível em: 
$<$ http://www.chinatax.gov.cn/eng/c101270/c101271/c5094511/content.html>. Acesso em: 14 de maio de 2020.

STATE TAXATION ADMINISTRATION OF THE PEOPLES'S REPUBLIC OF CHINA. State Taxation Administration Annual Report. 2019b. Disponível em: < http://www.chinatax.gov.cn/download/pdf/swnb2018en.pdf>. Acesso em: 29/05/2020.

WONG, Christine PW. Central-local relations revisited the 1994 tax-sharing reform and public expenditure management in China. China Perspectives, p. 52-63, 2000.

WORLDWIDE TAX SUMMARIES. China, People's Republic of. c2020. Disponível em: < https://taxsummaries.pwc.com/peoples-republic-of-china>. Acesso em: 01/06/2020.

ZHU, Ze. Essays on China's Tax System. $170 \mathrm{f}$. Tese (Doutorado em Gestão) - Instituto Erasmus de Pesquisa em Gestão, Escola Erasmus de Economia, Universidade Erasmus de Roterdã, Roterdã, 2007.

\section{CONTRIBUIÇÃO DE AUTORIA}

\section{NOTAS DE AUTOR}

Jaderson Goulart Junior - Concepção, coleta de dados, análise de dados, elaboração do manuscrito, revisão e aprovação da versão final do trabalho.

Demian Castro - Elaboração do manuscrito, participação ativa da discussão dos resultados, revisão e aprovação da versão final do trabalho.

\section{FINANCIAMENTO}

Não se aplica.

\section{CONSENTIMENTO DE USO DE IMAGEM}

Não se aplica

APROVAÇÃO DE COMITÊ DE ÉTICA EM PESQUISA

Não se aplica.

\section{CONFLITO DE INTERESSES}

Não se aplica.

\section{LICENÇA DE USO}

Este artigo está licenciado sob a Licença Creative Commons CC-BY. Com essa licença você pode compartilhar, adaptar, criar para qualquer fim, desde que atribua a autoria da obra.

\section{HISTÓRICO}

Recebido em: 29-09-2020

Aprovado em: 14-10-2020 